\title{
PENGARUH KUALITAS PELAYANAN FASILITAS TERHADAP KEPUASAN TARUNA PADA AKADEMI MARITIM CIREBON (STUDI KASUS PADA TARUNA AKADEMI MARITIM CIREBON)
}

\section{Rusmadi}

Akademi Maritim Cirebon (AMC)

Email: rusmadiamc@yahoo.co.id

\section{Abstract}

The Influence of Facility Service Quality on Cadet Satisfaction at Maritim Academy of Cirebon (Case Study of cadet at Maritim Academy of Cirebon). This study aims to examine the Effect of Service Quality and Facilities on Cadet Satisfaction at the Maritim Academy of Cirebon. The object under study is the service sector that is hospitality. The population in this study uses Non-Probability Sampling with a sampling technique that is an incidental sampling. The number of samples was 50 respondents. While data analysis uses quantitative methods and types of associative research. the results of this study indicate that Service Quality affects Cadet Satisfaction. This is proven by count <ttable (3.481>1.677), the facility has no effect on Cadet satisfaction. this can be proven by count $\langle t$ table (3.154> 1.677). Quality of Service and Facilities together affect the Cadet Satisfaction. This can be proved by the calculated value of 11.522 while the table value of 3.20. The simultaneous effect of service and facility quality on Cadet satisfaction is $30.2 \%$. The remaining $69.8 \%$ is influenced by other factors.

Keywords: Service Quality, Customer Satisfaction, and Facilities

\begin{abstract}
Abstrak
Pengaruh kualitas pelayanan fasilitas terhadap kepuasan Taruna Akademi Maritim Cirebon (studi kasus pada Taruna Akademi Maritim Cirebon). Penelitian ini bertujuan untuk menguji pengaruh kualitas pelayanan dan fasilitas terhadap kepuasan Taruna Akademi Maritim Cirebon. Populasi dalam penelitian ini menggunakan non probability sampling dengan teknik pengambilan sampel yaitu sampling insidential dengan jumlah sampel sebesar 50 responden. Untuk analisis data menggunakan metode kuantitatif dan jenis penelitian asosiatif. Hasil penelitian menunjukan bahwa kualitas pelayanan berpengaruh terhadap kepuasan Truna. Hal ini di buktikan dengan nilai thitung < ttabel $(3,481>1,677)$. Sedangkan untuk fasilitas tidak berpengaruh terhadap kepuasan Taruna yang dibuktikan dengan nilai thitung < ttabel $(3,154>1,677)$. Kualitas pelayanan dan fasilitas keduanya bersamasama berpengaruh terhadap kepuasan Taruna. Hal ini dapat dibuktikan dengan nilai fhitung sebesar 11,522 sedangkan nilai ftabel sebesar 3,20. Pengaruh kualitas pelayanan dan fasilitas secara simultan terhadap kepuasan Taruna adalah 30,2\%, adapun sisanya $69,8 \%$ dipengaruhi faktor lain.
\end{abstract}

Kata kunci: Kualitas Pelayanan, Kepuasan Taruna dan Fasilitas 


\section{Pendahuluan}

Dalam mengembangkan dan meningkatan kualitas sumber daya manusia pelayanan fasilitas pendidikan menjadi hal penting yang harus diperhatikan. Kualitas pelayanan fasilitas secara tidak langsung berkaitan dengan segala hal yang dipergunakan dan menunjang kelancaran proses pendidikan. Tidak dapat di pungkiri bahwa dalam pengelolaan pendidikan kualitas pendidikan tersebut juga didukung dengan sarana dan prasarana yang memadai sesuai dengan standar pendidikan terkait. Pengelolaan yang dimaksud agar dalam pelaksanaan dan pengguanaan fasilitas sarana dan prasarana berjalan secara efektif dan efisien sesuai dengan yang diharapkan.

Bentuk pelayanan yang harus ada dalam layanan pendidikan secara umum denim membagi menjadi 4 (empat) kelompok, yaitu: 1) sarana tenaga pengajar, 2) sarana fisik, 3) Sarana Administrasi, dan 4) Waktu. (Danim, 1994).

Kepuasan maupun ketidakpuasan Taruna merupakan perbandingan antara harapan Taruna dan kenyataan dari kualitas pelayanan yang dirasakan oleh Taruna yang menjadi tujuan perusahaan agar selalu dipuaskan. (Gasperz, 1997)

Layanan atau jasa ialah segala bentuk tindakan atau pekerjaan yang ditawarkan kepada orang lain dalam rangka memberikan kemudahan untuk kemudian saling memberikan manfaat satu sama lain, yang pada dasarnya berwujud dan tidak menghasilkan kepemilikan apapun. (Kotler \& Keller, 2009)

Kepuasan layanan dapat dipengaruhi melalui kualitas pelayanan yang di berikan oleh pihak akademi kepada para Taruna sehingga Taruna itu sendiri merasakan kepuasan atas fasilitas dari pelayanan tersebut. Kualitas pelayanan tersebut dapat berupa pelayanan yang terbaik dan dapat dirasakan oleh Taruna sebagai pengguna jasa. Selain kualitas pelayanan yang diberikan kepada konsumen, kepuasan Taruna dapat dipengaruhi juga melalui penyediaan fasilitas yang diberikan oleh Akademi. Penyediaan fasilitas yang diberikan atau disiapkan oleh Akademi tersebut harus memenuhi kebutuhan dan harapan para Taruna guna memberikan kepuasan pada Taruna.

Kualitas pelayanan berpusat pada pemenuhan kebutuhan dan keinginan serta ketepatan penyampaian untuk mengimbangi harapan para Taruna. Selain itu untuk memenangkan persaingan adalah dengan membuat sesuatu yang berbeda. Kualitas jasa berfokus pada upaya pemenuhan mengimbangi harapan Taruna. (Tjiptono, 2014)

Fasilitas yang ditawarkan oleh perusahaan jika ditanggapi oleh konsumen akan memperoleh peluang besar bagi tempat tersebut. Identifikasi harapan konsumen mengenai fasilitas yang diberikan oleh Akademi tersebut memberikan pengaruh kepada kepuasan Taruna. Dalam hal ini, pelayanan merupakan salah satu aspek yang penting dalam manajemen pengelolaan pelyanan dan sering dikatakan sebagai proses berlanjut. Disamping kualitas pelayanan yang baik, fasilitas juga turut berperan dalam menjaring konsumen. Fasilitas adalah sarana yang sifatnya mempermudah konsumen untuk melakukan suatu aktivitas. 
Rusmadi

Berdasarkan uraian di atas, maka yang menjadi suatu pertimbangan bagi penulis untuk membahas penelitian ini dengan judul "Pengaruh Kualitas Pelayanan dan Fasilitas terhadap Kepuasan Taruna Pada Akademi Maritim Cirebon”.

\section{Metode Penelitian}

Metode penelitian yang digunakan dalam penelitian ini yaitu dengan metode kuantitatif dengan jenis penelitian yang digunakan adalah penelitian asosiatif atau hubungan. Populasi dalam penelitian ini adalah Taruna Akademi Maritim Cirebon. Sampel dalam penelitian ini adalah non-probability sampling, dengan menggunakan teknik pengambilan sampel menggunakan insidental sampling.

\section{Hasil dan Pembahasan}

\section{A. Hasil}

\section{Uji Validitas}

Tabel 2 Kepuasan Taruna

\begin{tabular}{cccc}
\hline $\begin{array}{c}\text { Butir } \\
\text { Pertanyaan }\end{array}$ & Rhitung & Rtabel (5\%) & Hasil \\
\hline 1 & 0,561 & 0,279 & Valid \\
\hline 2 & 0,520 & 0,279 & Valid \\
\hline 3 & 0,574 & 0,279 & Valid \\
\hline 4 & 0,307 & 0,279 & Valid \\
\hline 5 & 0,416 & 0,279 & Valid \\
\hline 6 & 0,716 & 0,279 & Valid \\
\hline 7 & 0,637 & 0,279 & Valid \\
\hline 8 & 0,751 & 0,279 & Valid \\
\hline 9 & 0,649 & 0,279 & Valid \\
\hline 10 & 0,298 & 0,279 & Valid \\
\hline 11 & 0,325 & 0,279 & Valid \\
\hline 12 & 0,367 & 0,279 & Valid \\
\hline 13 & 0,304 & 0,279 & Valid \\
\hline
\end{tabular}

Berdasarkan tabel diatas terlihat bahwa $r_{\text {hitung }}>r_{\text {tabel }}$ artinya semua pernyataan untuk variabel kualitas pelayanan (X1) valid maka dapat disimpulkan variabel kualitas Pelayanan dapat digunakan dalam proses analisis data.

Tabel 3 Fasilitas

\begin{tabular}{cccc}
\hline $\begin{array}{c}\text { Butir } \\
\text { Pertanyaan }\end{array}$ & Rhitung & Rtabel & Hasil \\
\hline 1 & 0,512 & 0,279 & Valid \\
\hline 2 & 0,385 & 0,279 & Valid \\
\hline 3 & 0,409 & 0,279 & Valid \\
\hline 4 & 0,465 & 0,279 & Valid \\
\hline 5 & 0,489 & 0,279 & Valid \\
\hline
\end{tabular}




\begin{tabular}{llll}
\hline 6 & 0,406 & 0,279 & Valid \\
\hline
\end{tabular}

Berdasarkan tabel diatas terlihat bahwa $r_{\text {hitung }}>r_{\text {tabel }}$ artinya semua pernyataan untuk variabel fasilitas (X2) valid maka dapat disimpulkan variabel fasilitas dapat digunakan dalam proses analisis data.

Tabel 4 Kepuasan Taruna

\begin{tabular}{cccc}
\hline $\begin{array}{c}\text { Butir } \\
\text { pertanyaan }\end{array}$ & Rhitung & Rtabel & Hasil \\
\hline 1 & 0,414 & 0,279 & Valid \\
\hline 2 & 0,559 & 0,279 & Valid \\
\hline 3 & 0,518 & 0,279 & Valid \\
\hline 4 & 0,459 & 0,279 & Valid \\
\hline
\end{tabular}

Berdasarkan tabel diatas terlihat bahwa $r_{\text {hitung }}>r_{\text {tabel }}$ artinya semua pernyataan untuk variabel kepuasan Taruna (Y) valid maka dapat disimpulkan variabel kepuasan Taruna dapat digunakan dalam proses analisis data.

Tabel 5 Kualitas Pelayanan

\section{Reliability Statistics}

\begin{tabular}{|c|c|}
\hline $\begin{array}{c}\text { Cronbach's } \\
\text { Alpha }\end{array}$ & $\mathrm{N}$ of Items \\
\hline, 845 & 13 \\
\hline
\end{tabular}

Berdasarkan pada tabel diatas tampak bahwa nilai Cronbach's Alpha sebesar 0,845 atau > 0,70 variabel kualitas pelayanan (X1) adalah reliabel. Maka hal tersebut dapat digunakan dalam proses analisis data.

\begin{tabular}{l} 
Tabel 6 Fasilitas \\
Reliability Statistics \\
$\begin{array}{l}\text { Cronbach's } \\
\text { Alpha N of Items }\end{array}$ \\
\hline, $709 \quad 6$ \\
\hline
\end{tabular}

Berdasarkan pada tabel diatas tampak bahwa nilai Cronbach's Alpha sebesar 0,709 atau > 0,70 variabel Fasilitas (X1) adalah reliabel. Maka hal tersebut dapat digunakan dalam proses analisis data. 


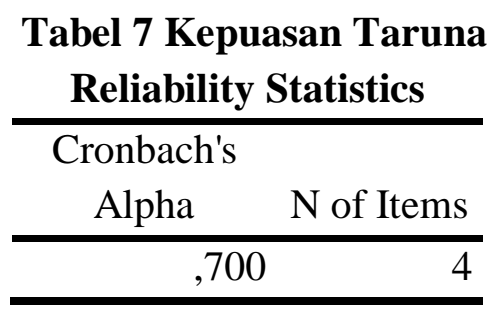

Berdasarkan pada tabel diatas tampak bahwa nilai Cronbach's Alpha sebesar 0,700 atau > 0,70 variabel Kepuasan Taruna (Y) adalah reliabel. Maka hal tersebut dapat digunakan dalam proses analisis data.

\section{Uji Normalitas}

Tabel 8

One-Sample Kolmogorov-Smirnov Test

\begin{tabular}{llr}
\hline & & Unstandardized Residual \\
\hline $\mathrm{N}$ & & 50 \\
Normal Parameters & Mean &, 0000000 \\
& Std. Deviation & 1,00448283 \\
Most Extreme Differences & Absolute &, 072 \\
& Positive &, 060 \\
& Negative &,- 072 \\
Test Statistic & &, 072 \\
Asymp. Sig. (2-tailed) & &, $200^{\text {c,d }}$ \\
\hline
\end{tabular}

a. Test distribution is Normal.

b. Calculated from data.

c. Lilliefors Significance Correction.

$\mathrm{d}$. This is a lower bound of the true significance.

Berdasarkan uji normalitas di atas dengan Kolmogorov-Smirnov test pada tabel 4.19, diperoleh nilai asymp.sig sebesar $0.200>0,05$. Maka dapat disimpulkan bahwa data variabel bebas dan variabel terikat berdistribusi normal.

\section{Uji Multikolonieritas}

Tabel 9 Uji Multikolonieritas

\begin{tabular}{llcc}
\hline \multirow{2}{*}{ Model } & \multicolumn{2}{c}{$\begin{array}{c}\text { Unstandardized } \\
\text { Coefficient }\end{array}$} \\
\cline { 3 - 4 } & & B & Std.Error \\
\hline 1 & (Constant) & & \\
& Kualitas_pelayanan &, 982 & 1,019 \\
& Fasilitas &, 982 & 1,019 \\
\hline
\end{tabular}


Berdasarkan tabel diatas menunjukan bahwa variabel kualitas pelayanan dan fasilitas untuk nilai VIF = 1,019 dibawah angka 10 dan nilai toleransinya lebih besar yaitu 0,982 dari nilai batas yang ditemukan 0,10. Maka dapat disimpulkan bahwa model regresi tersebut tidak terdapat problem multikolinearitas antar variabel independen karena telah memenuhi persyaratan ambang toleransi dan nilai VIF.

\section{a. Analisis Linier Berganda}

Tabel 10 Analisis Linear Berganda

\begin{tabular}{llcc}
\hline \multirow{2}{*}{ Model } & \multicolumn{2}{c}{$\begin{array}{c}\text { Unstandardized } \\
\text { Coefficient }\end{array}$} \\
\cline { 3 - 4 } & & B & Std.Error \\
\hline 1 & (Constant) & 7,267 & 2,239 \\
& Kualitas_pelayanan &, 094 &, 028 \\
& Fasilitas &, 198 &, 066 \\
\hline
\end{tabular}

Apabila kualitas pelayanan dan fasilitas tidak berubah maka kepuasaan Taruna masih ada, hal ini karena konsumen merasa cukup puas dan nyaman dengan fasilitas yang diberikan di Akademi Maritim Cirebon tersebut. Namun, apabila terjadi perubahan kualitas pelayanan dan fasilitas maka akan merubah kepuasaan Taruna.

\section{b. Koefisien Determinasi}

Tabel 11 Koefisien Determinasi

\begin{tabular}{lcccc}
\hline \multicolumn{5}{c}{ Model Summary } \\
\hline Model & $\mathrm{R}$ & R Square & $\begin{array}{c}\text { Adjusted R } \\
\text { Square }\end{array}$ & $\begin{array}{c}\text { Std, Error Of The } \\
\text { Estimate }\end{array}$ \\
\hline 1 &, 574 &, 329 &, 300 & 1,206 \\
\hline
\end{tabular}

Berdasarkan tabel 11 diatas menunjukan bahwa Nilai R Square sebesar 0,329 menunjukan kontribusi atau keefektifan model dari struktur variabel independen (kualitas pelayanan dan fasilitas) secara bersama-sama terhadap variabel dependen (keputusan pembelian) sebesar $32,9 \%$ dan sisanya $68,1 \%$ dipengaruhi oleh variabel lain yang tidak diteliti dalam penelitian ini. 


\section{c. Uji T}

Tabel 11 Kualitas Pelayanan

\begin{tabular}{llcc} 
& \multicolumn{1}{c}{ Model } & T & Sig. \\
\hline 1 & (Constant) & 7,016 &, 000 \\
\hline & Kualitas_pelayanan & 3,481 &, 001 \\
\hline
\end{tabular}

Berdasarkan hasil perhitungan, diperoleh nilai $t_{\text {hitung }}>t_{t a b e l}$ yaitu 3,481> 1,667 maka H0 ditolak dan Ha diterima. Artinya terdapat pengaruh yang positif dan signifikan variabel kualitas pelayanan terhadap kepuasaan Taruna.

Tabel 12 fasilitas uji T

\begin{tabular}{llcc}
\hline & \multicolumn{1}{c}{ Model } & T & Sig. \\
\hline 1 & (Constant) & 5,980 &, 000 \\
\hline & Kualitas_pelayanan & 3,154 &, 003 \\
\hline
\end{tabular}

Berdasarkan hasil perhitungan, diperoleh nilai $t_{\text {hitung }}>t_{\text {tabel }}$ yaitu 3,154> 1,667 maka H0 ditolak dan Ha diterima. Artinya terdapat pengaruh yang positif dan signifikan pada variabel fasilitas terhadap kepuasaan Taruna.

\section{d. Uji F}

Tabel 12 Uji F

\begin{tabular}{llcl}
\hline & \multicolumn{1}{c}{ Model } & F & Sig. \\
\hline 1 & $\begin{array}{l}\text { Regression } \\
\text { Resudial Total }\end{array}$ & 11,522 &, $000^{\circ}$ \\
\hline
\end{tabular}

Berdasarkan hasil perhitungan, diperoleh nilai $F_{\text {hitung }}>F_{\text {tabel }}$ yaitu sebesar 11,522>3,20. Dengan demikian maka H0 ditolak dan Ha diterima, dapat disimpulkan bahwa kualitas pelayanan dan fasilitas berpengaruh positif terhadap kepuasaan Taruna.

\section{B. Pembahasan}

\section{Pengaruh Kualitas Pelayanan terhadap Kepuasan Taruna}

Berdasarkan hasil pengujian hipotesis diperoleh hasil yang menyatakan bahwa tidak terdapat pengaruh kualitas pelayanan terhadap kepuasan Taruna, yang ditunjukan oleh uji t yang didapat nilai $t_{\text {hitung }}<t_{\text {tabel }} \quad\left(t_{\text {hitung }} 3,841<t_{\text {tabel }}\right.$ 1,677 ) maka $\mathrm{H}_{0}$ ditolak, yang artinya kualitas pelayanan mempunyai pengaruh yang positif dan signifikan terhadap kepuasan Taruna pada Akademi Maritim 
Cirebon. Hal ini dapat menunjukan bahwasanya kualitas pelayanan Akademi Maritim Cirebon dapat memberikan pengaruh paling besar pada kepuasan Taruna. Kualitas pelayanan Akademi Maritim Cirebon dapat mempengaruhi kepuasaan Taruna dikarenakan mempunyai pelayanan yang bagus, pelayanan yang cepat terhadap konsumen, sehingga hal tersebut harus dipertahankan dan lebih ditingkatkan lagi. Kualitas pelayanan yang baik akan menimbulkan kesan yang baik dari konsumen.

\section{Pengaruh Fasilitas Terhadap Kepuasan Taruna}

Berdasarkan hasil pengujian hipotesis diperoleh hasil yang menyatakan bahwa tidak terdapat pengaruh fasilitas terhadap kepuasan Taruna, yang ditunjukan oleh uji $t$ yang didapat nilai $t_{\text {hitung }}<t_{\text {tabel }}\left(t_{\text {hitung }} 3,154<t_{\text {tabel }} 1,677\right.$ ) maka $\mathrm{H}_{0}$ ditolak, yang artinya fasilitas mempunyai pengaruh yang positif dan signifikan terhadap kepuasaan Taruna Akademi Maritim Cirebon. Hal ini menunjukan bahwa variabel fasilitas mempunyai pengaruh terhadap kepuasaan Taruna. Apalagi jika fasilitas yang diberikan sangat memuaskan yang sesuai harapan konsumen dan kebutuhan konsumen maka dalam sebuah pelyananan mampu menarik perhatian dan mempengaruhi consumen untuk bisa lebih nyaman dengan fasilitas yang diberikan.

\section{Pengaruh Kualitas Pelayanan dan Fasilitas terhadap Kepuasan Taruna}

Berdasarkan hasil pengujian hipotesis diperoleh hasil yang menyatakan bahwa tidak terdapat pengaruh kualitas pelayanan dan fasilitas terhadap kepuasan Taruna. Hal ini ditunjukan oleh uji t yang didapat nilai diperoleh nilai $\mathrm{f}_{\text {hitung }}$ sebesar 11.522 sedangkan nilai $\mathrm{f}_{\text {tabel }}$ sebesar 3,20 dan nilai signifikansi sebesar 11.522> 0,005 berarti memiliki pengaruh yang signifikansi maka hipotesis yang diajukan $\mathrm{H}_{0}$ ditolak, artinya kualitas pelayanan dan fasilitas secara simultan atau bersama-sama mempunyai pengaruh yang positif dan signifikan terhadap kepuasaan Taruna pada Akademi Maritim Cirebon. Hal ini menandakan jika ketertarikan konsumen terhadap pelayanan yang diberikan oleh pihak Akademi Maritim Cirebon dilihat dari kualitas pelayanan dan fasilitas yang sesuai dengan kebutuhan dan keinginan konsumen. Dari hasil penelitian ini menunjukan bahwa kualitas pelayanan mempunyai pengaruh yang paling besar terhadap kepuasaan Taruna Akademi Maritim Cirebon. Kualitas pelayanan dan fasilitas yang baik dan sesuai dengan selera serta kebutuhan konsumen dapat merasa bangga dan merasa puas dengan fasilitas yang diberikan oleh Akademi Maritim Cirebon. 
Rusmadi

\section{Kesimpulan}

Hasil penelitian menunjukkan bahwa secara parsial variabel kualitas pelayanan memiliki pengaruh yang positif dan signifikan terhadap kepuasaan Taruna. Hasil penelitian menunjukkan bahwa secara parsial variabel fasilitas memiliki pengaruh yang positif dan signifikan terhadap kepuasaan Taruna. Hasil penelitian menunjukan bahwa secara simultan variabel kualatitas pelayanan dan fasilitas memiliki pengaruh yang positif dan signifikan terhadap kepuasaan Taruna. 
Pengaruh Kualitas Pelayanan Fasilitas terhadap Kepuasan Taruna

\section{BIBLIOGRAFI}

Danim, S. (1994). Media Massa Pendidikan. Bumi Aksara, Jakarta.

Gasperz, V. (1997). Manajemen Bisnis Total. PT. Gramedia Jakarta.

Kotler, P., \& Keller, K. L. (2009). Marketing management. 1. vyd. Praha: Grada, 2007, $788 \mathrm{~s}$.

Tjiptono, F. (2014). Pemasaran Jasa-prinsip, penerapan, dan penelitian. Yogyakarta: Andi Offset. 